\title{
Sistemas hidráulicos: procedimentos sustentáveis aplicáveis à manutenção dos edifícios
}

\author{
Rita de Cássia Teixeira Assis ${ }^{1 *}$, Maria Teresa Gomes Barbosa ${ }^{2}$ \\ *Autor de Contato: rita.assis@engenharia.ufjf.br \\ ${ }^{1}$ Engenheira Civil, Mestranda do programa de pós-graduação em Ambiente Construído, UFJF, Juiz de Fora, Brasil \\ ${ }^{2}$ Professora D. Sc., Departamento de Construção Civil, UFJF, Juiz de Fora, Brasil
}

\section{RESUMO}

O objetivo deste trabalho é analisar as manifestações patológicas recorrentes no sistema hidráulico e na cobertura das edificações e discutir sobre as atividades de manutenção que colaborem para a sustentabilidade. Para isso, é realizada uma revisão sistemática de literatura, buscando identificar as principais patologias e a partir dessa investigação, sugerir os procedimentos sustentáveis que podem ser adotados na etapa de manutenção das edificações residenciais, especialmente no que tange a manutenção preventiva, visando otimizar o uso de água e de energia. Pretende-se, com essa pesquisa, contribuir para a melhoria da qualidade dos sistemas em estudo, ressaltar a importância da realização da manutenção e destacar como essas ações podem minimizar os impactos ambientais provocados na fase de uso de uma edificação.

Palavras-chave: Instalações hidráulicas prediais; Manifestações patológicas; Sustentabilidade.

\section{ABSTRACT}


The objective of this work is to analyze the recurrent pathological manifestations in the hydraulic system and in the coverage of buildings and to discuss maintenance activities that contribute to sustainability. For this, a systematic literature review is carried out, seeking to identify the main pathologies and from this investigation, suggest the sustainable procedures that can be adopted in the maintenance phase of residential buildings, especially with regard to preventive maintenance, in order to optimize the use of water and energy. It is intended, with this research, to contribute to the improvement of the quality of the systems under study, to emphasize the importance of carrying out maintenance and to highlight how these actions can minimize the environmental impacts caused in the phase of using a building.

Key words: Building hydraulic installations; Pathological manifestations; Sustainability.

\section{RESUMEN}

El objetivo de este trabajo es analizar las manifestaciones patológicas recurrentes en el sistema hidráulico y en la cobertura de los edificios y discutir las actividades de mantenimiento que contribuyan a la sostenibilidad. Para ello, se realiza una revisión bibliográfica sistemática, buscando identificar las principales patologías $\mathrm{y}$, a partir de esta investigación, sugerir los procedimientos sostenibles que se pueden adoptar en la fase de mantenimiento de edificaciones residenciales, especialmente en lo que se refiere al mantenimiento preventivo, con el fin de optimizar el uso. de agua y energía. Se pretende, con esta investigación, contribuir a la mejora de la calidad de los sistemas en estudio, enfatizar la importancia de realizar mantenimientos y resaltar cómo estas acciones pueden minimizar los impactos ambientales provocados en la fase de uso de un edificio.

Palabras clave: Construcción de instalaciones hidráulicas; Manifestaciones patológicas; Sustentabilidad.

\section{INTRODUÇÃO}

Em relação à construção civil, "patologia" diz respeito ao estudo de falhas e defeitos que alteram o aspecto estrutural e visual de uma edificação. Assim, o estudo de patologias nas construções é parte imprescindível na garantia de qualidade e na prevenção dos problemas que levam à degradação das edificações (NAZÁRIO e ZANCAN, 2011).

A degradação prematura das edificações manifestada pelo decréscimo de desempenho é um problema atual e frequente, podendo ser observada na queda da segurança, utilização, estabilidade, durabilidade e na estética das edificações. Como solução, apresenta-se a gestão do sistema de manutenção, devendo englobar possibilidades para preservar as características originais da edificação e também garantir a prevenção da perda de desempenho proveniente da degradação dos seus sistemas, elementos ou componentes (ABNT, 2012).

Diversos problemas relacionados à durabilidade da edificação podem ser resolvidos durante o processo de construção, caracterizado como a primeira fase da vida de um imóvel. Um projeto eficaz, orientações adequadas, o atendimento às exigências impostas pelas normas e pelo programa de uso, a qualidade dos materiais empregados e o acompanhamento técnico adotado na construção são procedimentos importantes que vão propiciar essa durabilidade. Em contrapartida, durante a 
segunda fase, a de uso, uma série de complicações pode aparecer devido ao desgaste ocasionado por usos indevidos. Faz-se necessário, portanto, procedimentos regulares e programados de manutenção para a conservação e eficácia da destinação da edificação, evitando o surgimento de patologias e deteriorações inesperadas, permitindo previsão segura de gastos periódicos (MARTINS, 2017).

Leal et al (2008) afirma que em uma instalação predial de água, alguns serviços são necessários para, em certos casos, repor as condições originais e, em outros, refazer algum tipo de componente, dentro dos padrões de qualidade que possibilitem um melhor uso da edificação. Assim como qualquer outro sistema que compõe um edifício, o sistema de cobertura também está passível de sofrer com as manifestações patológicas que possam surgir durante a sua vida útil, comprometendo assim, o nível de desempenho esperado. Dessa forma, medidas de manutenção devem ser planejadas buscando atender aos requisitos de desempenho e sustentabilidade, especialmente, relacionadas à redução do consumo de água e energia.

O crescimento da consciência ecológica aponta para a importância da adoção de um modelo de gestão e planejamento urbano adeptos à questão da sustentabilidade, ou seja, buscando conciliar desenvolvimento socioeconômico à preservação e manutenção dos recursos naturais disponíveis. Essa problemática tem ocupado um lugar relevante no conjunto de reflexões globais, sobretudo a partir do século XX, quando começaram a acontecer as grandes conferências mundiais acerca de questões relacionadas à degradação do meio ambiente e a eficácia das instituições e das agências mundiais quanto ao planejamento do desenvolvimento urbano e da qualidade de vida da população (ALMEIDA, 2019).

Visto a importância da gestão das atividades de manutenção para a garantia do desempenho das construções, é possível destacar com incomplexidade a necessidade do estudo das patologias existentes a fim de preservar a vida útil dos componentes de uma edificação habitacional.

Diante disso, o objetivo principal desse estudo é analisar as manifestações patológicas recorrentes no sistema hidráulico e na cobertura das edificações habitacionais, abordando sobre as atividades de manutenção que colaborem para construções mais sustentáveis, reduzindo os impactos ambientais na fase de uso. Dentre os objetivos específicos estão: (i) Levantar as manifestações patológicas mais frequentes nas instalações hidráulicas e na cobertura de edifícios residenciais; (ii) Discutir sobre a importância das atividades de manutenção predial; e (iii) apresentar propostas de soluções sustentáveis que contribuam para a sustentabilidade.

\section{FUNDAMENTAÇÃO TEÓRICA}

As manifestações patológicas estão presentes na maioria das edificações, seja com maior ou menor intensidade, variando no período da aparição e/ou na forma como se manifestam nos edifícios (PIRES, 2013). Estudos de Araújo, Medeiros e Silva (2019) constatam que 66\% das prováveis causas e origens dos acidentes em edificações com mais de dez anos estão relacionados à deficiência com a manutenção, perda precoce de desempenho e deterioração acentuada.

Conforme define o Instituto Brasileiro de Avaliações e Perícias de Engenharia (IBAPE), as anomalias podem ser endógenas (da própria edificação), exógenas (provocadas por fatores externos), naturais (advindas de fenômenos da natureza) ou funcionais (pela degradação natural dos sistemas construtivos). Carvalho Júnior (2018) ressalta ainda que as principais causas de patologias de origem endógena são: falhas de projeto (40\%), falhas de execução (28\%), qualidade dos materiais (18\%), uso das instalações (10\%), e diversos (4\%). 
De acordo com Marinho (2011), as coberturas são umas das áreas mais críticas da construção, contribuindo para elevadas patologias construtivas associadas a más soluções técnicas e deficiente execução. Alguns detalhes, como os fatores climáticos e aspectos de dimensionamento devem ser considerados na elaboração desta componente do edifício.

Teixeira et al. (2011) afirmam que patologias frequentes nos sistemas hidráulicos de um edifício não envolvem sérios riscos à vida dos seus usuários. Porém, elas costumam causar transtornos, aborrecimentos e desconfortos, em geral associados aos sintomas comuns de suas manifestações.

Para Vieira (2016), os sistemas hidráulicos prediais não estão recebendo a atenção necessária e indispensável para que tenham um bom desempenho de acordo com a vida útil da edificação. Essa condição é decorrente de alguns fatores, tais como: execução de obras sem os projetos de instalações; redução de custos nas instalações; e o fato de serem ocultas.

Além disso, a falta de observação às normas pertinentes e a falta de qualidade dos materiais utilizados na construção do edifício, bem como da mão de obra e eventuais negligências dos construtores, podem ocasionar vícios, defeitos construtivos e, consequentemente, danos ao proprietário da edifícação (CARVALHO JR, 2013).

Fatores já citados anteriormente, aliados à falta de manutenção, tem criado despesas extras aos usuários que, em alguns casos, com menos de cinco anos de uso, já necessita consumir recursos financeiros em reparos. Reparos estes que poderiam inteiramente ser evitados (MARINHO, 2011). Araújo, Medeiros e Silva (2019) afirmam que a previsão e o planejamento das possíveis intervenções ao longo da vida útil dos edifícios são fundamentais para reduzir o aparecimento de anomalias. A manutenção preventiva, quando feita por meio de intervenções regulares e planejadas, é essencial para conservação e eficácia da destinação da edificação. Também é importante para a segurança do usuário que essa manutenção seja realizada periodicamente.

De acordo com a normalização brasileira, NBR 5674:

"A omissão em relação à necessária atenção para a manutenção das edificações
pode ser constatada nos frequentes casos de edificações retiradas de serviço muito
antes de cumprida a sua vida útil projetada (VUP), causando muitos transtornos
aos seus usuários e um sobrecusto intensivo dos serviços de recuperação ou
construção de novas edificações" (ABNT, 2012, p.2).

A NBR 15.575 (ABNT, 2013) avalia a manutenibilidade como um requisito para "manter a capacidade do edifício e de seus sistemas e permitir ou favorecer as inspeções prediais, bem como as intervenções de manutenção previstas no Manual de Uso, Operação e Manutenção".

Os empreendimentos da indústria da construção civil são atualmente um dos maiores causadores de impactos ambientais. As atividades relacionadas à construção, operação e demolição de edifícios promovem a degradação ambiental por meio do consumo excessivo de recursos naturais e através da geração de resíduos sólidos.

O conceito de sustentabilidade no ambiente construído demanda por sistemas construtivos que se integrem ao meio ambiente, adaptados as necessidades de uso, produção e consumo humano, preservando os recursos naturais para as futuras gerações, utilizando soluções que permitam o desenvolvimento econômico e o bem-estar social (SOARES, 2017).

Edificações que possuem um sistema para captar e acumular água da chuva, para um uso futuro, apresentam uma redução no consumo de água tratada e, consequentemente, diminuição do valor pago por esse serviço. As cidades sustentáveis apresentam como princípio a melhoria do bem-estar e qualidade de vida de seus habitantes, priorizando a integração do planejamento e da administração do meio urbano, juntamente com os sistemas ecológicos e ambientais (SEBRAE, 2019). 
Dessa forma, o tema sustentabilidade nas práticas da manutenção predial apoia-se na perspectiva de aplicação de atividades de manutenção, de melhoria e modernização das edificações na etapa de uso e operação, visando a contribuição para a sustentabilidade (ABREU, 2012).

\section{METODOLOGIA}

\subsection{Considerações iniciais}

A estratégia metodológica adotada para a realização deste estudo foi a Revisão Sistemática de Literatura (RSL), que, segundo Maiorino e Bertoli (2017), pode ser considerada uma metodologia de trabalho que visa criar um protocolo de busca de literatura de maneira criteriosa. "A expressão sistemática significa que a revisão deve seguir um método explícito, planejado, responsável e justificável" (DRESCH; LACERDA e ANTUNES JÚNIOR, 2015, p. 142).

Como justificativa para essa revisão, tem-se a necessidade de esclarecer as seguintes indagações: "Quais são as patologias recorrentes no sistema hidráulico e de cobertura das edificações habitacionais?" e "Como as atividades de manutenção podem contribuir para a sustentabilidade das edificações?”. Definidas essas questões motivadoras, foi possível iniciar o planejamento da pesquisa de títulos relacionados ao tema proposto.

O processo de revisão foi dividido em duas etapas: (i) identificação e seleção dos artigos e (ii) análise sistemática do conteúdo.

\subsection{Identificação e seleção dos estudos}

Para o levantamento dos trabalhos já publicados, as plataformas de busca utilizadas foram: Periódicos CAPES e Google Acadêmico, utilizando um recorte temporal de 2012 até o momento da pesquisa, filtrando o tipo de material em artigos e em qualquer idioma. Para a plataforma de busca Google Acadêmico utilizou-se a limitação de palavras-chave para serem inclusas no título, além disso, citações e patentes foram desconsideradas.

Para definição das strings, investigações preliminares foram realizadas, tendo a finalidade de refinar a busca sistematizada. Considerando que os resultados da busca com palavras-chave isoladas foram excessivamente amplos, optou-se por utilizar termos mais específicos, sendo adotados os conjuntos apresentados no quadro 1.

Quadro 1. Termos de busca.

\begin{tabular}{|c|c|c|c|c|}
\hline Etapas & $1^{a}$ busca & $2^{\mathrm{a}}$ busca & $3^{a}$ busca & $4^{\mathrm{a}}$ busca \\
\hline $\begin{array}{c}\text { Termos } \\
\text { utilizados }\end{array}$ & $\begin{array}{l}\text { PATOLOGIAS } \\
\text { EM SISTEMAS } \\
\text { HIDRÁULICOS }\end{array}$ & $\begin{array}{c}\text { PATOLOGIAS EM } \\
\text { COBERTURAS }\end{array}$ & $\begin{array}{l}\text { MANUTENÇÃO } \\
\text { PREDIAL }\end{array}$ & $\begin{array}{l}\text { EDIFICAÇÕES } \\
\text { SUSTENTẢVEIS }\end{array}$ \\
\hline
\end{tabular}

Para a seleção dos artigos, alguns critérios de exclusão e inclusão foram estabelecidos, e após triagem, os artigos passaram por um processo de aprovação para serem avaliados na RSL.

Os critérios estabelecidos para a exclusão dos artigos foram: (a) Artigos repetidos; (b) Trabalhos em que o texto completo não esteja disponível online; (c) A partir da leitura do título, o artigo não apresenta aderência à questão motivadora; (d) A partir da leitura do resumo, o artigo não apresenta 
aderência ao assunto investigado; (e) A partir da leitura do artigo, não há aderência aos objetivos propostos. Caso haja dúvidas em algumas das etapas, o artigo deverá ser mantido para análise na próxima fase.

Os critérios estabelecidos após seleção dos artigos para que pudessem ser incluídos e avaliados foram: (a) $\mathrm{O}$ estudo deve incluir em sua proposta o levantamento de patologias no sistema hidráulico e/ou cobertura de edificações; (b) Deve considerar a manutenção desses sistemas, considerando a importância para a sustentabilidade das edificações. Estudos que atenderam somente um dos critérios de inclusão também foram avaliados.

\subsection{Análise sistemática do conteúdo}

Nessa etapa aconteceu a síntese e organização dos estudos encontrados. Após a aplicação dos critérios estabelecidos na etapa anterior, os artigos selecionados foram analisados e organizados de acordo com os temas e conteúdos abordados que sejam relevantes para o entendimento entre as patologias existentes e a importância da manutenção a fim de contribuir para edificações mais sustentáveis.

Quadro 2. Quantitativo de artigos selecionados.

\begin{tabular}{|c|c|c|c|c|}
\hline Etapas & $\mathbf{1}^{\mathbf{a}}$ busca & $\mathbf{2}^{\mathbf{a}}$ busca & $\mathbf{3}^{\mathbf{a}}$ busca & $\mathbf{4}^{\mathbf{a}}$ busca \\
\hline Periódicos CAPES & 01 & 01 & 02 & 03 \\
\hline Google Acadêmico & 04 & 03 & 02 & 03 \\
\hline Total & \multicolumn{4}{|c|}{$\mathbf{1 9}$ artigos } \\
\hline
\end{tabular}

\section{RESULTADOS E ANÁLISES}

\subsection{Manifestações patológicas}

Há uma enorme variedade de materiais, equipamentos e componentes do sistema predial hidráulico como: bombas hidráulicas, tubos, registros, válvulas, conexões, tanques, entre outros. Essa variedade contribui para o aparecimento das manifestações patológicas nas instalações hidráulicas, que vão desde simples erros até falhas mais graves.

Barros, Silva e Paes (2016) destacam que, em muitos casos, a detecção de todas as falhas e inconformidades nas instalações hidráulicas é dificultada, visto que muitos de seus componentes estão embutidos nas edificações e não existe "as built" dessas obras. Isso compromete a identificação da origem dos problemas e sua relação com as normas e legislações vigentes.

Em um levantamento, realizado por Paz et al. (2016), é abordado que em edificações com mais de vinte anos é comum encontrar diversos pontos de infiltração provenientes de instalações hidráulicas. A umidade nos materiais construtivos origina e abre caminhos para outros tipos de patologias na edificação.

Em relação aos vazamentos os mesmos ocorrem por diversos fatores, entre eles destaca-se, principalmente, o desgaste natural de sistemas hidráulicos antigos e instalações hidráulicas malfeitas. Existem vazamentos de fácil detecção, percebidos através de testes rápidos ou da simples 
inspeção nos produtos, e outros mais difíceis de serem detectados no qual é necessário o auxílio do aparelho de geologia para identifica-los. Os pontos mais críticos das tubulações estão nas conexões/junções (SANTOS e LAGE, 2020). Segundo Carvalho Junior (2013) as principais anomalias decorrem:

i) Patologias em instalações prediais de água fria: oriundas de rupturas em tubulações, contaminação da água em tubulações e reservatórios, vazamento em tubulações embutidas (Figura 1), ruídos e vibrações, incidência de ar nas tubulações e desacoplamento em juntas de tubulações.

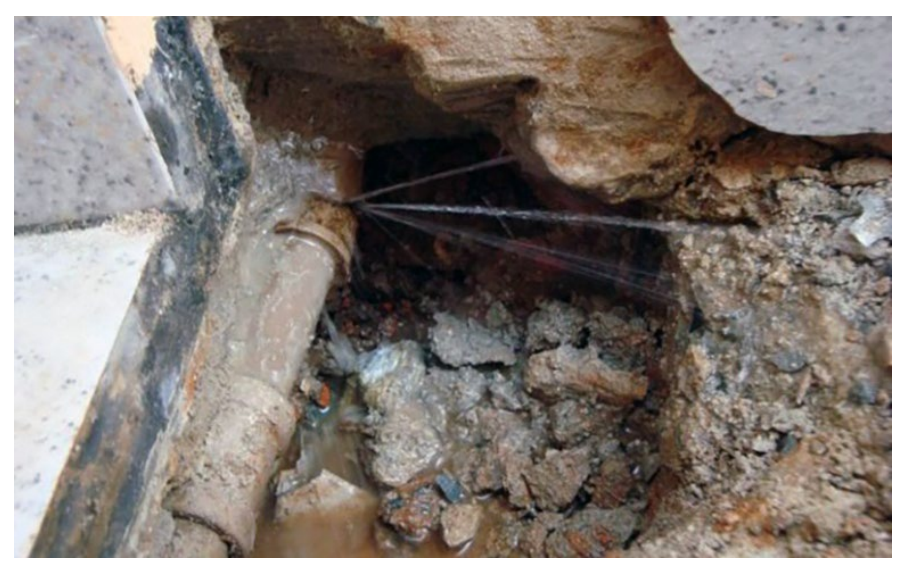

Figura 1. Vazamento localizado em tubulação embutida. Fonte: SAAE Salto/SP, 2021.

ii) Patologias em instalações prediais de água quente: decorre da perda de calor nas tubulações, deficiência no aquecimento da água, deformação e ruptura em tubulações de plástico, vazamentos em aquecedores a gás e corrosão em tubulações (Figura 2).

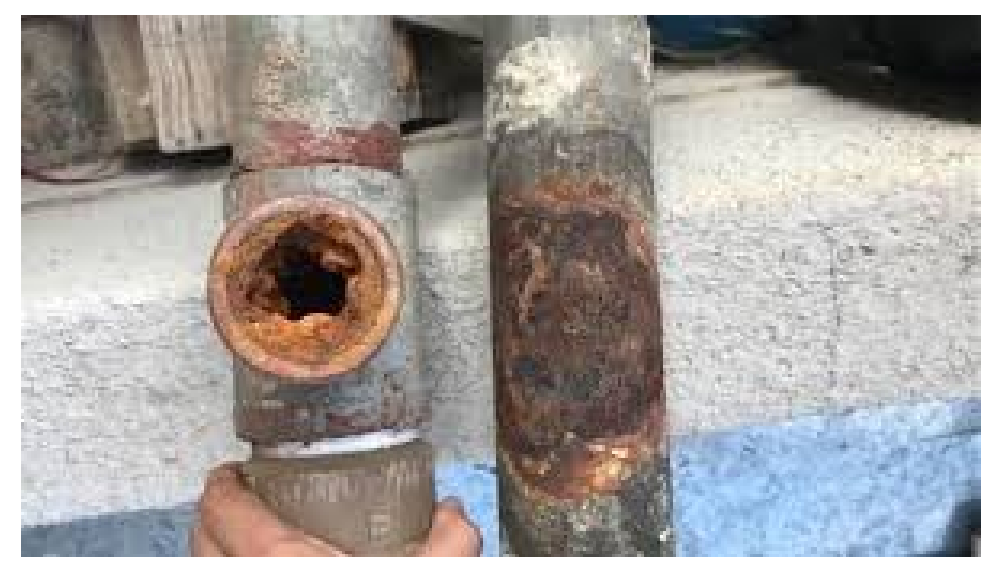

Figura 2. Corrosão em tubulação de água quente.

Fonte: Confea, 2021.

iii) Patologia em coberturas: Silva e Góes (2019) afirmam que as coberturas têm como principal agente patológico a água cuja fonte geradora é, majoritariamente, as chuvas. Essas apresentam muitos vazamentos pelos seus sistemas de escoamento de águas pluviais (calhas e tubos de queda) ou pela integridade do próprio telhado. Esses vazamentos e infiltrações 
(Figura 3), de acordo com Oliveira et al. (2019), podem gerar o apodrecimento de forros de madeira, derretimento dos forros de gesso e gerar bolores, fungos, manchas e corrosão das armaduras em lajes de concreto.

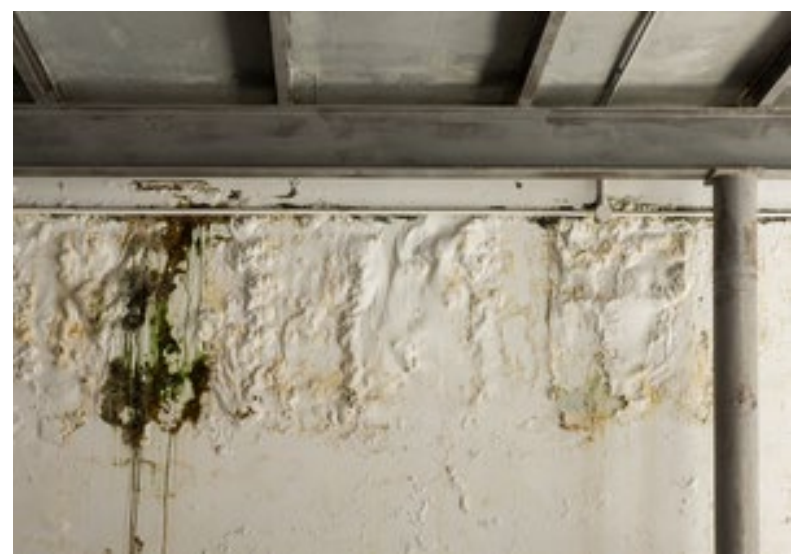

Figura 3. Infiltração em cobertura.

Fonte: Leroy Merlin, 2021.

O sistema de cobertura está passível a existência de manifestações patológicas durante a sua vida útil. Os problemas podem estar relacionados ao telhado em si, ou a sua estrutura de cobertura. Para sistemas com telhas cerâmicas e suporte em madeira, diferenciam-se os tipos de patologias observadas. Nesse caso, as patologias mais frequentes são a quebra ou o acumulo de detritos nas telhas, que geram problemas de infiltração no edifício (PINHEIRO et al. 2018).

iv) Patologias em instalações prediais de águas pluviais: decorrente da infiltração de água nas coberturas, transbordamento de calhas, vazamentos em calhas e condutores, entupimentos em calhas e condutores (Figura 4), acúmulo de água em coberturas horizontais, ressecamento de condutores aparentes.

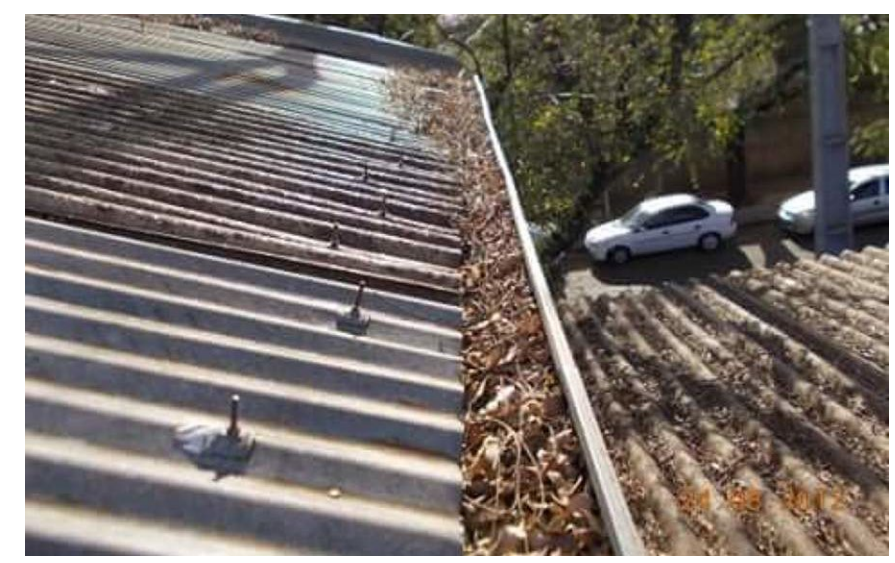

Figura 4. Acúmulo de detritos em cobertura. Fonte: Habitíssimo, 2021.

\subsection{Edificações sustentáveis}


A necessidade de minimização dos impactos ao meio ambiente gerados pelas edificações e a difusão dos conceitos relacionados ao desenvolvimento sustentável levaram o setor a procurar construções que apresentem um melhor desempenho ambiental.

O primeiro ponto a se considerar na busca deste tipo de edificação é que as preocupações devem começar desde o projeto, prosseguirem durante a construção e participarem da etapa de utilização. Dentre as principais ações, é possível destacar: adoção de um modelo de projeto, no qual as soluções são avaliadas considerando o ciclo de vida da edificação, incluindo custos de operação, uso, manutenção e desmontagem das edificações, e não apenas seus custos iniciais; utilização de soluções que aumentem a flexibilidade das edificações e facilitem reformas e modernizações, como por exemplo, a reposição de componentes e subsistemas; utilização de materiais e componentes que resultem em menor impacto ambiental ao longo do seu ciclo de vida; garantir desde a concepção, um empreendimento voltado à economia de energia e água, redução de custos ao longo da vida útil do empreendimento e bem estar ao usuário.

Macêdo e Martins (2015) afirmam que a sustentabilidade desperta o interesse de todos os setores de produção, e do setor da construção civil de forma mais significante. Edificações que geram a sua própria energia, equipadas com sistemas de reaproveitamento de águas ou qualquer outra prática que as tornem mais sustentáveis são cada vez mais almejadas por um crescente número de consumidores, vindo a impactar positivamente na preservação da natureza e na minimização dos impactos ambientais.

O reaproveitamento de água pluvial apresenta vários aspectos positivos, pois permite a redução no consumo de água potável acarretando a diminuição do custo de água fornecido pelas companhias de abastecimento, reduzindo o risco de alagamentos e contribuindo para a preservação do meio ambiente através da redução da exploração de recursos hídricos. A facilidade na composição do sistema é a principal característica para o aproveitamento da água da chuva, o que implica diretamente a redução dos custos de implantação e manutenção. Desse modo, o uso de cisternas, por exemplo, apresenta baixo custo e pode ser eficaz para o uso excessivo da água potável pelo ser humano, tornando viável economicamente (TUGOZ, BERTOLINI e BRANDALISE, 2017).

Conto, Oliveira e Ruppenthal (2017) destacam que o desenvolvimento constante de novas técnicas construtivas e a crescente adesão de diversas certificações ambientais vêm contribuindo para o aumento do desempenho do ambiente construído, associado à sustentabilidade.

Certificações ambientais de edificações são uma importante ferramenta para a transformação do setor da construção civil. Através delas, é possível mensurar, avaliar e mitigar os impactos ambientais da implantação, construção e uso de uma edificação, contribuindo para o desenvolvimento sustentável do planeta.

Diante do exposto recomenda-se:

i) Aproveitamento da água pluvial: com a incidência das chuvas tem-se o potencial de recolhimento das águas e a possível utilização das mesmas para fins de serviço como: bacias sanitárias, torneiras de jardim e reservas de incêndio. Para isso, é necessário empregar um sistema para recolher, filtrar e armazenar as águas pluviais. Estas são coletadas em áreas impermeáveis da edificação, como calhas, estacionamentos e coberturas. Após esse recolhimento, são encaminhadas para um filtro e armazenadas em um reservatório para posterior utilização.

De acordo com Tugoz, Bertolini e Brandalise (2017), a economia de água potável gerada através da implantação de um sistema para aproveitamento de água pluvial se aproxima de $60 \%$. Além do benefício econômico, haverá menor exploração dos recursos naturais e diminuição de enchentes intensificadas pelo escoamento superficial. 
ii) Equipamentos hidráulicos economizadores: são elementos hidrossanitários com a finalidade de reduzir o consumo de água desnecessária para a sua operação, sendo alguns deles: arejadores de torneiras, registros reguladores de vazão, bacias sanitárias com caixa acoplada de volume reduzido e válvulas ou caixas de descarga com acionamento duplo.

Esses dispositivos podem ser adotados em construções novas ou serem empregados na fase de manutenção da edificação, em substituição à equipamentos que apresentam maior consumo. Miranda (2019) destaca que a redução do consumo de água decorrente da instalação desses dispositivos pode chegar até $40 \%$.

iii) Energia fotovoltaica: pode ser obtida através da fixação de painéis com lâminas finas e sensíveis nas coberturas existentes; por meio de telhas solares, que funcionam também como cobertura; ou ainda com a utilização de tintas capazes de absorver luz solar e transformar em energia elétrica.

O armazenamento dessa energia solar é feito em baterias ou ainda, podem ser diretamente ligados à rede elétrica. Quando a energia coletada não é totalmente utilizada pela residência, pode ser revendida para a concessionária de energia elétrica, reduzindo a compra de energia e gerando um lucro para os moradores.

Embora essas tecnologias de geração de energia solar sejam inicialmente mais caras, segundo Cabral e Vieira (2012), os possíveis benefícios socioambientais trazidos por essa fonte de energia, como o alcance de áreas isoladas, a geração de empregos, a não emissão de gases de efeito estufa, compensam o seu custo. Além disso, esse investimento será recompensado por meio da redução do pagamento à concessionária que fornece energía elétrica.

iv) Dispositivos para redução do consumo de energia: além de investir em fontes alternativas para a geração de energia elétrica, é importante também optar por equipamentos de baixo consumo. Dispositivos com acendimento / fechamento automático, lâmpadas de baixo consumo e aproveitamento de luz e ventilação natural são itens que podem contribuir para a redução dos impactos ambientais gerados pelas edificações em uso.

Além das recomendações citadas, diversas modificações podem ser implantadas nos procedimentos de manutenção predial para obtenção de melhorias na sustentabilidade das edificações já existentes e em fase de uso.

Entretanto, apesar de todas as vantagens apresentadas, o uso dessas alternativas sustentáveis ainda são pouco utilizadas no Brasil devido, principalmente, ao seu custo inicial elevado se comparado com os sistemas construtivos convencionais. Importante ressaltar que esse investimento é compensado ao longo do tempo.

A manutenção predial com práticas sustentáveis é uma nova perspectiva no campo da construção civil. Sua aplicação efetiva nos edifícios residenciais podem ser estendidas para outros tipos de edificação, ampliando, dessa forma, a extensão das medidas de redução de impactos ao meio ambiente.

\section{CONCLUSÕES}


Inovações, através do emprego de opções tecnológicas durante a etapa de construção e a fase de uso, são fundamentais para que a edificação colabore para o desenvolvimento sustentável.

O sistema hidráulico predial, além de assegurar o fornecimento de água predial, bem como, garantir a qualidade da água e a distribuição de maneira adequada, traz consigo benefícios ambientais provenientes de sua instalação eficaz, garantindo a fácil manutenção preventiva, levando também em consideração a constatação de vazamentos, contribuindo para evitar o desperdício de água.

A economia de água potável é evidente, especialmente, quando a infraestrutura está preparada para garantir a coleta e armazenamento da água da chuva, para ser reaproveitada posteriormente, como por exemplo, para irrigação de jardins e lavagem de pisos e carros.

Pelo fato de ficarem embutidas e ocultas, as instalações hidráulicas, em geral, não recebem a atenção necessária, resultando muitas das vezes em improvisos e utilização de materiais de baixa qualidade, comprometendo futuramente o bom desempenho da edificação.

Além do projeto e execução serem crucias para o bom desempenho das coberturas, é necessária uma manutenção periódica, a fim de evitar acúmulo de detritos e infiltrações. Com investimentos nesses sistemas, diversos benefícios econômicos e ambientais são gerados, além de agregar valor comercial à edificação.

A partir da breve apresentação das possíveis manifestações patológicas do sistema hidráulico predial e das coberturas das edificações, fica evidente o quanto o projeto se torna indispensável, evitando erros nas montagens das instalações, utilizando materiais de qualidade e, principalmente, promovendo as atividades de manutenção necessárias à conservação da vida útil e bom desempenho desses sistemas.

Dessa forma, o tema sustentabilidade nas práticas da manutenção predial apoia-se na perspectiva de aplicação de atividades de manutenção, de melhoria e modernização das edificações na etapa de uso e operação, visando a diminuição de manifestações patológicas e a redução dos impactos ambientais, contribuindo para edificações com maior durabilidade e mais sustentáveis.

\section{AGRADECIMENTOS}

CNPQ - Conselho Nacional de Desenvolvimento Científico e Tecnológico - Brasil

\section{REFERÊNCIAS}

Associação Brasileira de Normas Técnicas. (2012). NBR 5674. Manutenção de Edificações Requisitos para o sistema de gestão de manutenção. Rio de Janeiro.

Associação Brasileira de Normas Técnicas. (2013). NBR 15.575: Edificações Habitacionais Desempenho. Rio de Janeiro.

Abreu, W. G. Identificação de práticas sustentáveis aplicadas às edificações. (2012). $169 \mathrm{f}$. Dissertação (Mestrado em Engenharia Civil) - Universidade Federal Fluminense, Niterói, 2012.

Almeida, S. C. C. (2019). Indicadores de sustentabilidade: análise da aplicabilidade da NBR ISO 37120:2017 sob a perspectiva da engenharia urbana. 118 f. Dissertação (Mestrado em Engenharia Urbana) - Universidade Federal de São Carlos, São Carlos, 2019. 
Araújo, N. M. C.; Medeiros, M. O.; Silva, M. R. (2019). Um estudo multicaso quanto à relação entre os Manuais do Usuário e a legislação vigente. HOLOS, [S.1.], v. 7, p. 1-9, dez. DOI: $\underline{10.15628 / \text { holos.2019.6217. }}$.

Barros, F. A.; Silva, D. V. C.; Paes, R. P. (2016). Instalações prediais hidráulicas e sanitárias em escolas públicas: patologias e satisfação dos usuários. REEC, v.11, n.2, p.39-50. DOI: $\underline{10.5216 / \text { reec.V11i2.32880 }}$

Cabral, I.; Vieira, R. (2012). Viabilidade econômica x viabilidade Ambiental do uso de Energia Fotovoltaica no caso Brasileiro: Uma abordagem no período recente. III Congresso Brasileiro de Gestão Ambiental. Goiânia.

Carvalho JR, Roberto. (2013). Patologias em sistemas prediais hidráulicossanitários. São Paulo: Editora Blucher.

Carvalho JR., R. (2018). Patologias em sistemas prediais hidráulico-sanitários. Editora Blucher, $3^{\mathrm{a}}$ edição revista. São Paulo - SP.

Conselho Federal de Engenharia e Agronomia. Disponível em: https://www.confea.org.br/ Acesso em: Março de 2021.

Conto, V.; Oliveira, M. L.; Ruppenthal, J. E. (2017). Certificações ambientais: contribuição à sustentabilidade na construção civil no Brasil. Revista Gestão da Produção Operações e Sistemas, [S.1.], v. 12, n. 4, p. 100, nov. DOI: 10.15675/gepros.v12i4.1749.

Dresch, A.; Lacerda, D. P.; Antunes Júnior, J. A. V. (2015). Design science research: método de pesquisa para avanço da ciência e tecnologia. Porto Alegre: Bookman.

Habitíssimo. Disponível em: https://www.habitissimo.com.br/ Acesso em: Março de 2021.

Instituto Brasileiro de Avaliações e Perícias de Engenharia. (2012). Norma de inspeção predial nacional. São Paulo.

Leal, C. M. S. et al. (2008). Diagnóstico da manutenção preventiva das instalações prediais de água fria do CEFET-PB, Unidade João Pessoa. PRINCIPIA, nº 16, João Pessoa.

Leroy Merlin. Disponível em: https://www.leroymerlin.com.br/ Acesso em: Março de 2021.

Macêdo, A. T.; Martins, M. F. (2015). A sustentabilidade urbana sob a ótica da construção civil: um estudo nas empresas construtoras de Campina Grande-PB. Revista de Gestão Ambiental e Sustentabilidade, v. 4, n. 1., pp. 139-157. Universidade Nove de Julho São Paulo, Brasil.

Maiorino, A. V.; BertolI, S. R. (2017). Características arquitetônicas e o decaimento sonoro de salas acopladas: uma revisão da literatura. PARC Pesquisa em Arquitetura e Construção, Campinas, SP, v. 8, n. 3, p. 194-204.

Marinho, M. J. P. S. (2011). Reabilitação predial em Portugal e no Brasil. Mestrado Integrado em Engenharia Civil - 2010/2011 - Departamento de Engenharia Civil, Faculdade de Engenharia da Universidade do Porto, Portugal.

Martins, G. (2017). A manutenção preventiva das edificações: o olhar dos gestores. 2007. $122 \mathrm{f}$. Dissertação (Mestrado) - Universidade Federal de Santa Catarina, Florianópolis.

Miranda, Z. L. B. (2019). Estimativa de redução de consumo de água proporcionado por aparelhos economizadores em comparação com aparelhos convencionais nos blocos 14, 15, 16 e 17 do IFTO 
- Campus Palmas. Trabalho de Conclusão de Curso, Instituto Federal de Educação, Ciência e Tecnologia, Palmas.

Nazário, D.; Zancan, E. C. (2011). Manifestações das patologias construtivas nas edificações públicas da rede municipal de Criciúma: inspeção dos sete postos de saúde. Artigo submetido ao Curso de Engenharia Civil - Universidade do Extremo Sul Catarinense, Criciúma.

Oliveira, M. R.; Oliveira, T. N.; Araújo, S. C. (2019).Patologias nas edificações, seu diagnóstico, e suas causas. In: IV Colóquio Estadual de Pesquisa Multidisciplinar. Anais....

Paz, L.; Costa, L.; Paula, M.; Almeida, W.; Fernandes, F. (2016). Patologias causadas pelo levantamento de umidade em um prédio em Palms - TO town. Revista Eletrônica em Gestão, Educação e Tecnologia Ambiental, 20 (1), 174-180. DOI: 10.5902/2236117019063

Pinheiro, C. N. P.; Barbosa, A. R.; Reis, V. D.; SaleS, L. H. F. (2018). Análise de Manifestações Patológicas em um Casarão Histórico Localizado na Cidade de Belém-PA. In: Congresso Brasileiro de Pontes e Estruturas, 2018, Rio de Janeiro. Anais....

Pires, J. R. (2013). Patologias na construção dos edifícios. Caso de estudo, edifício da FICASE na Cidade da Praia. 2013. 2285. Tese (Licenciatura) - Faculdade de Arquitectura. Universidade Jean Piaget de Cabo Verde, Palmarejo Grande, Cidade da Praia.

Serviço de Abastecimento de Água de Sato/SP. Disponível em: https://saaesalto.sp.gov.br/ Acesso em: Março de 2021.

Santos, F. P.; Lage, E. G. S. (2020). Patologias dos sistemas hidráulicos e sanitários da Escola Dom Domingos Carrerot. Engineering Sciences, v.8, n.1, p.17-26. DOI: 10.6008/CBPC2318$\underline{3055.2020 .001 .0003}$

Serviço Brasileiro de Apoio às Micro e Pequenas Empresas - Cidades Resilientes e Sustentáveis. 2019. 60f. Cuiabá, MT. Disponível em: http://sustentabilidade.sebrae.com.br/ Acesso em: Janeiro/2021

Silva, V. M. F.; Góes, B. P. (2019). Uma Abordagem sobre as Perícias de Engenharia na Manutenção Preventiva das Edificações. Revista Científica Semana Acadêmica. v.1. DOI: 10.35265/2236-6717-semanaacademica-v1n178-6.

Soares, R. R. (2017). A sustentabilidade aplicada na elaboração de centros de distribuição no Brasil. Revista de Gestão Ambiental e Sustentabilidade, v. 6, n. 3, pp. 1-14. Universidade Nove de Julho São Paulo, Brasil.

Teixeira, P. C. et al. (2011). A influência das variáveis microclimáticas na decisão pelo uso da bicicleta em centros urbanos: uma revisão da literatura. REEC, nº 2 34-50. ISSN: 2179-0612.

Tugoz, J. E.; Bertolini, G. R. F.; Brandalise, L. T. (2017). Captação e aproveitamento da água das chuvas: o caminho para uma escola sustentável. Revista de Gestão Ambiental e Sustentabilidade, v. 6, n. 1, pp. 26- 39. Universidade Nove de Julho, São Paulo, Brasil.

Vieira, P. C. C. (2007). Patologias em instalações hidro-sanitárias de edifícios residenciais na zona centro-sul de Manaus (AM): Diagnóstico e Terapia. 122 f. Dissertação (Engenharia de Processos) - Universidade Federal do Pará, Belém. 